\title{
Sustainable resources of Urban Economy
}

\author{
Reza POURVAZIRY, Architect, Chair of Urban Economy Forum \\ Fazileh DADVAR-KHANI, Professor of Geography, University of Tehran and Visiting Scholar at York University \\ S. Ananthakrishnan - Senior Advisor - UN-HABITAT, Secretariat General of Urban Economy Forum
}

\begin{abstract}
:
One of the main approaches to sustainable urbanization strategy is to find appropriate resources for promoting the quality of life via developing infrastructure and extending facilities and support urban life by facilitating public access to meet their needs.

Based on that we can approach a new urban economy based on sustainable resources and a specific diagram and discipline will participate in it. To realize this idea a clear statement and belief are needed. We expect that the outcome may be under undue pressure of the global political and economic forces because the new model is looking for creating fundamental changes to the current trends and turning to the new paradigm and world development system.

To reach this level of transformation this article will focus on 3 cities with different scales, knowing that the scale plays an important role in municipal finance, so:

1- This article will review the top alternative models of the current urban economy.

2- It will examine and analyze the interaction between understandings, recognizing the main challenges of important points between the concepts of life at a macro perspective; the current state of economic circulation in cities and expressing clear key points.

3- This article will be based on the city Prosperity Index of United Nations and also on indexes of the quality of life in order to introduce a model of sustainable urban lifestyle, which will be introduced as a 'dream'. As planners, we need to help cities promote self-reliance by redesigning the city in such a way that there will be a balance between external dependency and self-reliance

4- It will provide some examples of top priorities on sustainable resources to achieve the goals.
\end{abstract}

\section{Keywords}

Urban resource, economy, city prosperity index, Toronto, Victoria city, Collingwood

\section{Introduction}

Before analyzing alternative models of urban economy and resources it is important to review current urban economy models for cities. For example, Canadian cities follow central rules and regulations and they have the same municipal finance in their urban economic system. There is tolerance between an independent municipality and two different municipalities under the supervision of the central government. Different municipalities will have different authority framework and flexibility in actions.

All cities can be understood in terms of a theoretical framework that combines two main processes, namely, the dynamics of agglomeration/polarization, and the unfolding of an associated nexus of locations, land uses and human interactions (Allen J. Scott Michael Storper,2015:1). The city as a creative field is representative of deferent ideology, approaches and models of management. 
Current models of urban economics are varying based on different systems of urban management. Urban management is mainly rooted in the ideology which is behind the management systems.

One of the most dominate Ideology in operating the cities is "Capitalism "The spirit of capitalism is the product of a recursive process that operates via a feedback loop between economy and culture through justifications grounded in material arrangements (Boltanski and Chiapello 2005). Some governments with capitalist ideology believe that the city as an autonomous existence should be able to govern and run their budget independently. By authenticating to the available financial capital in cities, they focus on the cities as an engine for producing money or they should follow a mechanism that can generate wealth; consequently, it should be able to benefit individuals and attract investors to generate wealth.

This is a view that raises some important concepts such as self-governance, the independence of the urban economy from the national macro economy, as well as the independence from the national budgets. So based on this idea, there are unlimited financial resources in the city and the governors are not limited to use these resources; they can decide about managing the financial resource to promote their goals. In this context, all the components and the holistic of the city complex are at the disposal of the mayor, and he/she will be able to manage the city with all available facilities.

The Second view which has a very different dimension to the management system is the socialism approach. Socialism is both an economic system and an ideology (in the non-pejorative sense of that term). A socialist economy features social rather than private ownership of the means of production. (Internet Encyclopedia of philosophy, https://iep.utm.edu/socialis/, uploaded 2020). This ideology has more focused on public needs. In this ideology, it is believed that everyone must have the effective freedom to meet their basic needs for food, shelter, health care, and so on. With the slogan of social justice the ideology tries to look at the cities as a social institution that everyone should have equal access to places, opportunities and services. This is a crucial fulfillment, and one demanded by minimal standards of justice and decency. However, a good society must set its goals higher; it must enable people not merely to survive, but also to flourish (ibid). From this perspective, national resources are used to improve the quality of life of citizens. Many Scandinavian and left-wing countries have adopted this model, and there are many examples of this approach can be found in the world.

There is another approach regarding the critiques that have been made about the most common ideologies, Prominent among critiques of capitalism are accusations that capitalism is inherently exploitative, unsustainable and creates economic inequality, is anti-democratic and leads to an erosion of human rights while it incentivizes imperialist expansion and war. On the other hand, some of the primary criticisms of socialism are claims that it creates distorted or absent price signals, results in reduced incentives, causes reduced prosperity, has low feasibility, and that it has negative social and political effects (https://courses.lumenlearning.com/suny-internationalbusiness/chapter.

The third approach tries to impose more control over the city management and consequently they are limiting the urban authorities from managing the city freely due to the unwillingness to divide power. This situation creates various dependencies for cities on provincial and federal governments. Also, this model of the city governing ties the financial aspects and economy of the cities to national and macro economy and make it dependent on the national decision-makers and authorities. It means the management model will be up-down and the limited power is given to local managers on the scale of the city. It also limits the opportunity and ability to exploit the available resources. 
The fourth approach is some kind of unplanned operation model for cities. This model is moving between different ideologies and approaches, so there cannot find a specific and clear distinction. Also, there is neither a clear plan nor a clear philosophy for how to deal with urban issues, and urban management is a vague mix of different domains and approaches. Whereas urban spaces are increasingly facing challenges related to political economies and meeting the needs of communities.

Thus, we are facing different approaches and different models of urban management. Cities constitute complex socio-ecological systems in which activities on multiple scales interact to create development towards transformative change (Folke et al. 2010) this transformative change needs a transformative capacity building. Ideas of transformative capacity can be traced to the field of management science-well before this term was integrated into urban sustainability discourse (Castán Broto, et.al 2019).

\section{Capacity building, urban economy and municipal finance}

Wolfram (2016) identifies a set of components determining the extent of transformative capacity in urban areas that enable or drive purposive systemic change towards sustainability. These fall into three categories: (1) agency and forms of interaction, (2) development processes and (3) relational dimensions. The second set of criteria (development processes) refers to system awareness, collective visions, practical experimentation, reflexivity, capacity building, and institutional mainstreaming. On the one hand, insights about system awareness draw on the traditional management literature and associated insights related to strategic knowledge production required for organisational change (Garud and Nayyar 1994). So from this aspect urban management can organize and implement the capacities based on available facilities, authorities and opportunities, and can create sustainable resources for the urban economy. The main question that arises is how these resources are calculated?

From this perspective, the city is considered as an important opportunity for social and individual demonstrations, the direct participation of citizens, communities or civil society organizations. Therefore, it is believed that cities should have everything that is included in the definition of development.

Capacity building is a keyword for urban development. It is part of the new jargon that expresses the not-sonew concepts that were embraced and championed by Habitat II. Urban capacity building means empowerment for the governance, planning and management of cities and settlements is about handing down authority. It is about increasing efficiency, enhancing the effectiveness and ensuring the sustainability of development by passing responsibility to those people, communities and enterprises to whom efficiency, effectiveness and sustainability matter (Wakely,2020).

So we need to know how we can properly activate these capacities. As we know one of the most important foundations of sustainability is creating appropriate access to resources, building stable and increasing capacities and is the reinforcement of citizen's participation.

In analyzing the role of citizen participation in economic prosperity it is essential to understand that there are not all-inclusive responses to this issue given the diversity of cities in size and character and the constraints they face in intergovernmental relations. 
Participation can be applied in various political, social and cultural dimensions with a variety of models. The key to this discussion is a focus on building a resilient future through investing in sustainable infrastructure and reducing consumption and waste. The main key factor in effective participation occurs as a result of the presence, it means, if the city can maximize the presence of people, participation will increase and more resources will be activated.

The second issue is to identify sustainable resources that can imitate themselves so that they are not only nonconsumable but also able to reproduce themselves. This cyclic trend can be lead to sustainable resources which is an important issue that needs to be addressed.

The next issue is implementation. This process relies on the ecological potential and social potential that adjusted with the capacity. In this regard, the limit of development is a critical debate. Knowing the carrying capacity is a fundamental aspect in regional or urban planning. The capacity of resources, environment, culture, and infrastructure reveals the urban comprehensive carrying capacity to survive. It is an important concept to understand the true limit of development. Otherwise, having big aspirations can be against development. That is, if we want to force an issue on a city that is beyond the level of its resources and somehow exceeds the tolerance of that city, we lead such a city to instability by over-exploiting resources.

With the intention of planning process and the most basic step, we need to provide a complete knowledge of the variety of characteristics of the city. The more complete and deeper this knowledge is, the more it helps us make the right decisions. The model in which we can develop resources in a balanced way and with a stable cycle is very complex and contextual model. So that we need a separate study for each city based on its situation a consequently we will have a specific model for each city.

In other words, sustainability will be a result of balancing between production and consumption of the resources and it can build an economy based on regenerated capacities. The core of this issue is the need for a deep understanding of sources, knowing the capacities and limitations; otherwise, we will not be able to have accurate knowledge and correct evaluation and consequently we won't be able to manage the city correctly.

For example urban density plays an important role so that the balance between urban density and available resources is a critical issue that should be addressed. Many of the world's cities don't have a proper assessment of their condition, for example, are not able to assess the different cost of constructing a road, within areas with different density rate. By assessing cities the correct knowledge of their real resources can be collected and used properly. Therefore density is an essential issue that can play the main role in urban management, even in the post-corona era, indicators have shown that it is possible to control more populations in densely populated areas (Adlkha. D, Samis, J.F, 2020)

\section{Research methodology}

In the present study, a descriptive method based on a comparative approach has been used. 4 Economic schools of thought in urban management were the basis of our comparison and analysis, which are the ideology of capitalism, socialism, Maximizing the governmental control over the city budget and finally the 
unplanned operation model. On the other hand, costs and revenues and the city's economy in general were analyzed on three different scales. Because it is believed that the scale of the city plays a decisive role in how it is managed. Hence, the statistical population consists of 3 cities with different scales.

This paper examines how cities in different scales of Large, mid-sized and small cities, with populations between 23,000 and 3 million, are managing their financial resource and how the municipalities finance playing different roles in cities with different sizes?

Table 1

\begin{tabular}{|c|c|c|c|}
\hline \multicolumn{4}{|c|}{ CITY SIZE \& POPULATION } \\
\hline City & Size $(\mathrm{km} 2)$ & 2020 Population & $\begin{array}{c}2016 \text { Population } \\
\text { (Census Canada) }\end{array}$ \\
\hline Toronto & $630 \mathrm{~km} 2$ & 3.03 million & 2.73 million \\
\hline Victoria & $19.47 \mathrm{~km} 2$ & 385,999 & 117,135 \\
\hline Collingwood & $33.46 \mathrm{~km} 2$ & 23,755 & 21,800 \\
\hline
\end{tabular}

The required data was extracted mainly from the Census Canada, Other statistical sources were also used to match some data accordingly. Then, based on these data and based on the theoretical framework of the research, the economic situation of cities in different scales were analyzed.

\section{Urban Economy and city scale}

All Canadian cities face fiscal and governance problems unique to their sizes, economies, housing situations and population demographics.

Effective engagement is a fundamental part of good government. An involved community generates opportunities for individuals with diverse views to come together and share their ideas with officials and authorities and effectively participate in decision making progress. It's also an opportunity to build capacity for improving the City plans, programs and services. And for this reason, we selected three cities of Toronto as a large city, Victoria as a medium-size city and Collingwood as a small city. The main factors have been investigated based on the Census of Canada mostly 2016 data.

\subsection{Toronto}

The case of Toronto with 3.03 million shows the level in which interdependent spheres of economy and governance impact the urbanization of space. In the context of the City of Toronto, the municipality has been successful in gaining increased financial resources by the Ontario government; however, they have faced challenges in re-investing these assets in local communities and responding to problems from an anticipatory governance standpoint (Bird, Broadbent, Slack, Taylor, 2015). In cities like Toronto politics arguably plays a central role in whether local participation can be effective because questions are often raised on the extent to 
which the objectives of a particular political ideology overwhelms the participatory nature of citizens in influencing economic conditions (Côté and Fenn, 2014).

Graph 1

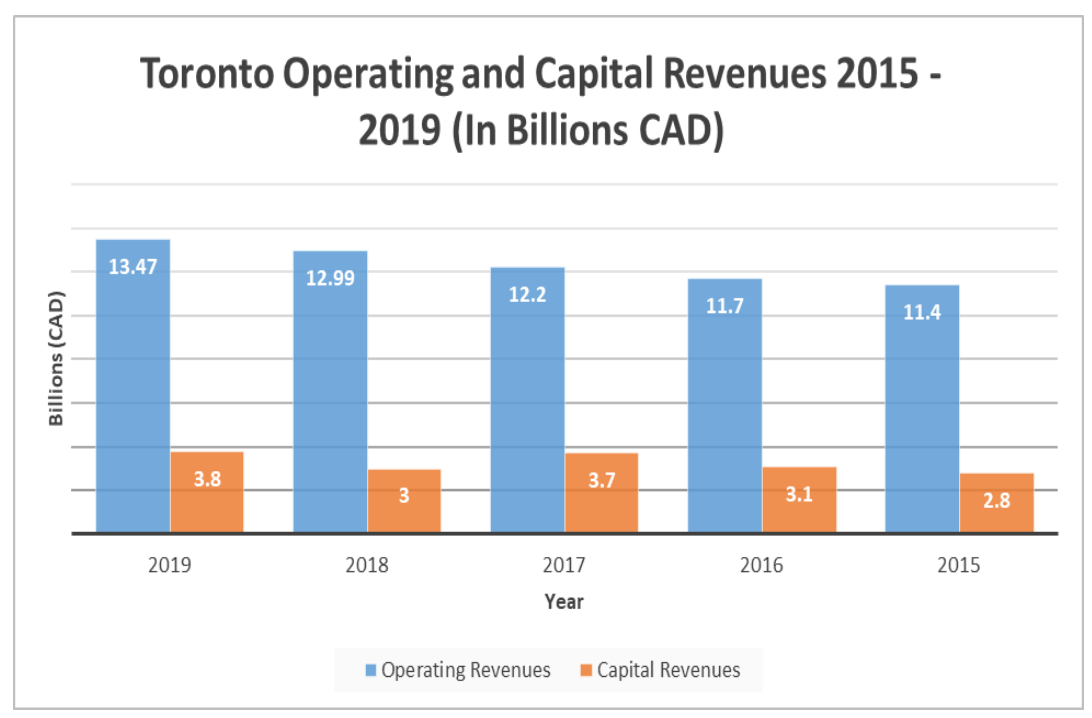

Operating revenues have been consistently increasing for Toronto within the last five years in Low slope to cover municipal programs and services. Capital revenues have also been increasing to cover the costs for existing and new infrastructure projects including new development.

Graph 2

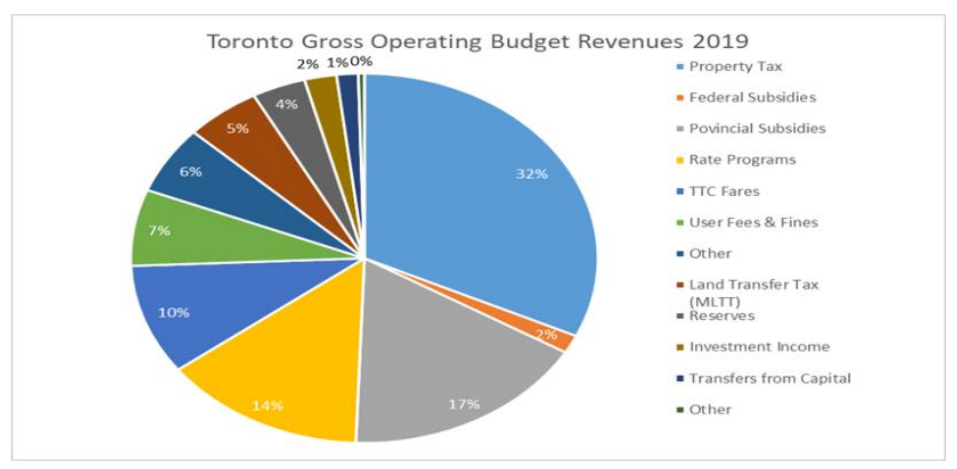

Property tax revenue is Toronto's single largest revenue source (32\%) from residential and business property owners for municipal purposes followed by provincial subsidies (17\%), rate programs (14\%) and TTC fares (10\%). This is consistent throughout the last three years. 


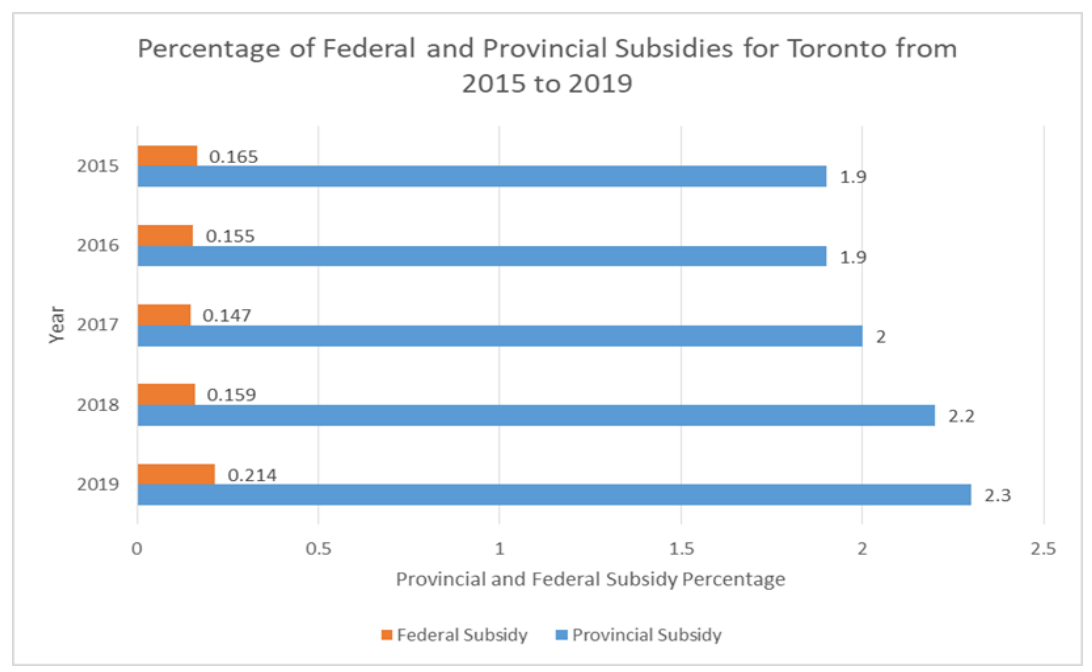

Toronto receives most of its subsidies from the provincial government with a steady increase throughout the last five years.

Graph 4

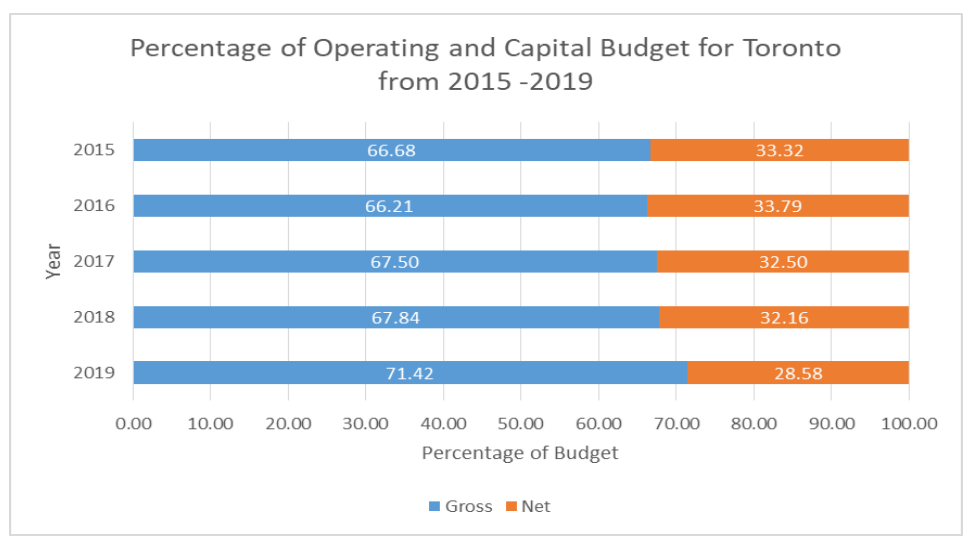

Approximately 68\% of Toronto's revenues come from the operating budget with a continuous increase in the last five years. Hence, the capital budget has been decreasing in the last five years. Victor and Collingwood do not report net revenues for both their operating and capital budgets.

Graph 5

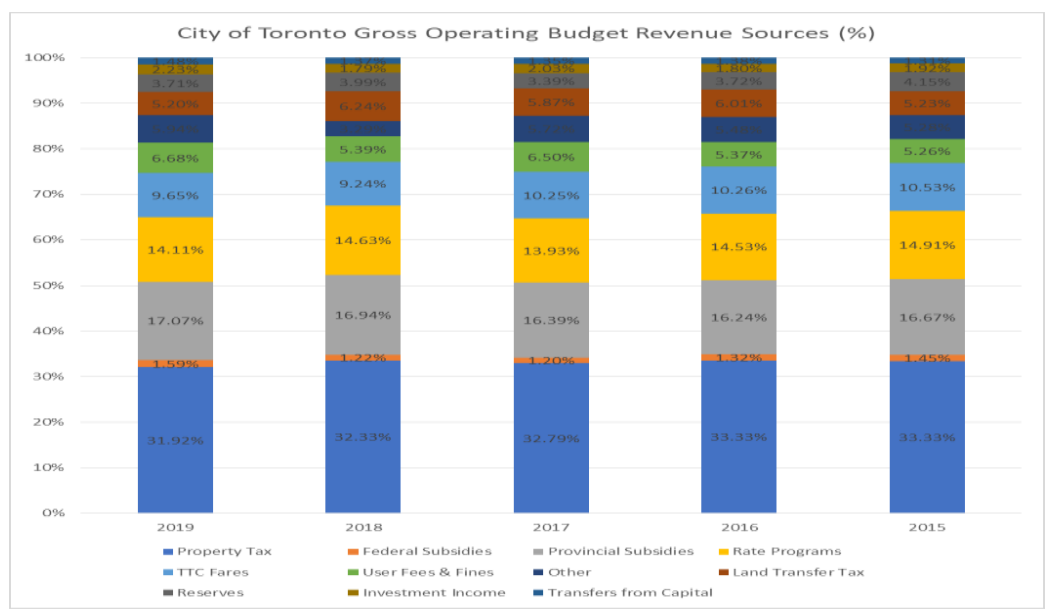


The above graph is a breakdown of the City of Toronto's Gross Operating Budget Revenue listed by sources. Toronto's most significant revenue sources were from property taxes that made up 31.9\% (2019), 32.3\% (2018), 32.8\% (2017), 33.3\% (2016), and 33.3\% (2015). The next significant revenue sources were from provincial subsidies $17.1 \%$ (2019), 16.9\% (2018), 16..4\%(2017), 16.2\% (2016), and 16.7\% (2015). The third largest revenue source was from rate programs which generated 14.11\% (2019), 14.6\% (2018), 13.9\% (2017), and $14.5 \%$ (2016), and $14.9 \%$ (2015). The next highest revenue sources from largest to smallest was TTC Fares, User Fees \& Fines, land transfer taxes, reserves, and investment income, and Transfers from Capital Budget. Other category included categories that were not pertinent to this report and were small sources of revenue.

Graph 6

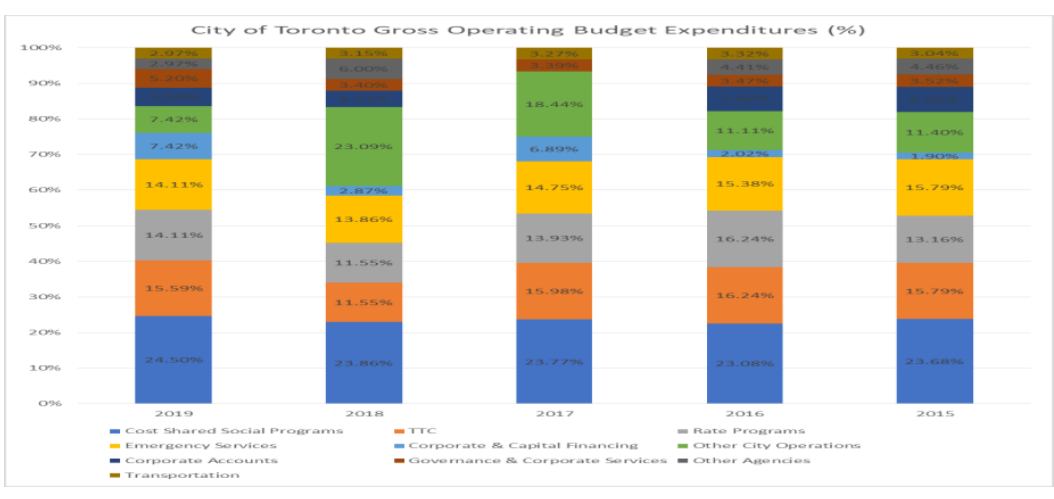

The above graph is a breakdown of the City of Toronto's Operating Budget Expenditures in percentage. The most significant expenditures are Cost Shared Social Programs, TTC, Rate Programs, Emergency Services, Corporate \& Capital Financing, Cooperate Accounts, Governance \& Corporate Services, Other Agencies, and Transportation. Other City Operations made up a large portion of city expenditures but included expenditures that were small and not pertinent to this report

\subsection{The City of Victoria}

The City of Victoria, in British Columbia as a sample of the medium-size city is studied. In the Annual Report, 2018, the goal the city has been indicated as follows: "Victoria is a leading-edge capital city that embraces the future and builds on the past, where human well-being and the environment are priorities, where the community feels valued, heard and understood and where City Hall is trusted" (Ibid 2018). An investigation into the mid-sized city of Victoria city offers insight into the interplay of urban infrastructure and community involvement in economic development.

Victoria is known as a regional commercial hub, and as the Capital City, Victoria is well-positioned to play a leadership role in the Capital Region. Victoria has faced challenges in increasing their taxes, being dependent 
on provincial support. The financial goal of the city is to maximize and where possible consolidate City-owned assets and put increased revenue from City-owned property to best and highest use including market-rate commercial leases (City Of Victoria, British Columbia, Annual Report, 2018: 21). Interestingly, in a community like Victoria where factors of Capital Revenues may be comparatively worse than other research sample cities, one could contend that a boost in local investment and contribution to municipal finance could support urban infrastructure (Côté and Fenn, 2014). Studies investigating fiscal stability in cities are required to develop sustainable conditions and that financial instability is a factor in the uncertainty surrounding the viability of the community (Côté and Fenn, 2014). In a place like Victoria, participation of citizens and local communities in municipal finance by increased public participation, local governance efforts, and engagement in a verity of programs related to a sustainable environment and inclusive spaces could be the main element in revitalizing the community.

Graph 7

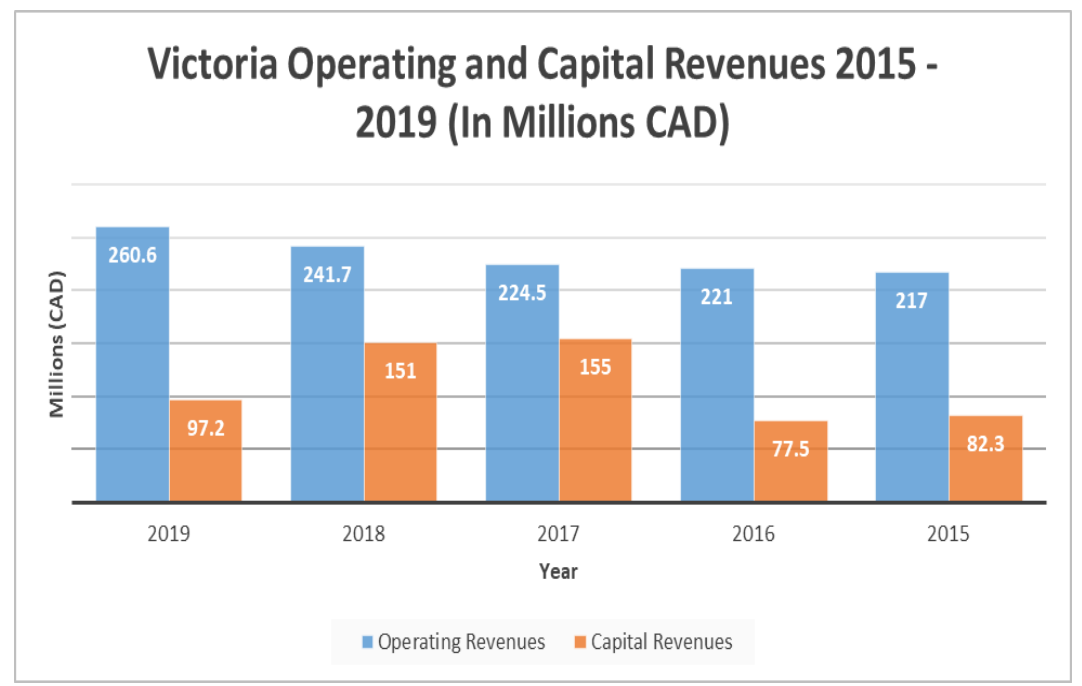

Graph 8

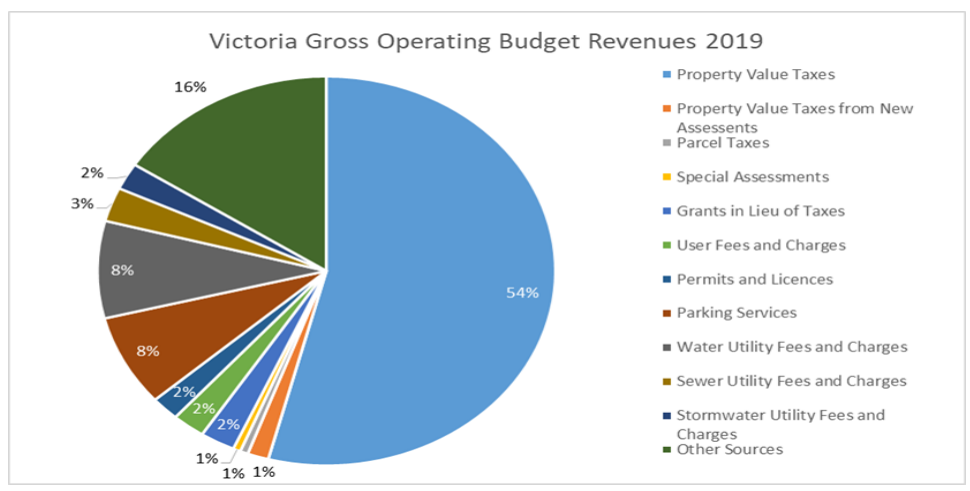

Property tax revenue is Victoria's single largest revenue source $(55 \%)$ followed by other (15\%) and water and sewer fees ( $9 \%$ and $7 \%$ respectively) in the last three years. Other income is comprised of a variety of revenue sources: Victoria Conference Centre's revenue generated from parking and room rentals, miscellaneous revenues (tax certificates, penalties, bus shelter advertising, rezoning fees and multi-purpose revenue from the 
Save-On- Memorial Centre, and lastly enhancement revenues from real estate leases and transfer from property taxes to a storm water utility.

\section{Graph 9}

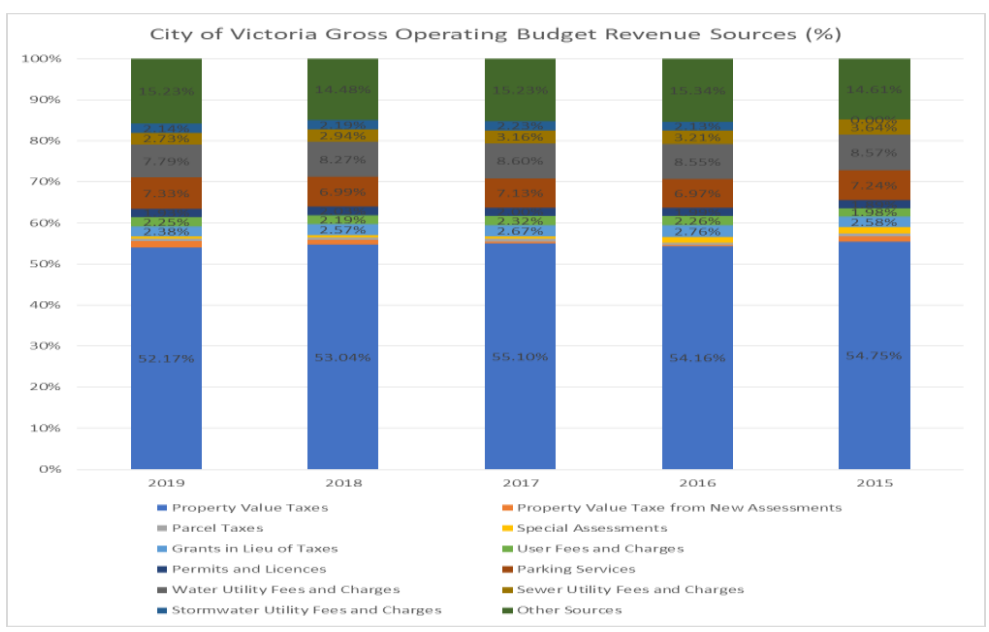

The above graph is a breakdown of the City of Victoria's gross Operating Budget Revenue Sources. The most significant revenue was from Property value taxes, followed by Water Utility fees, and Parking Services.

Graph 9

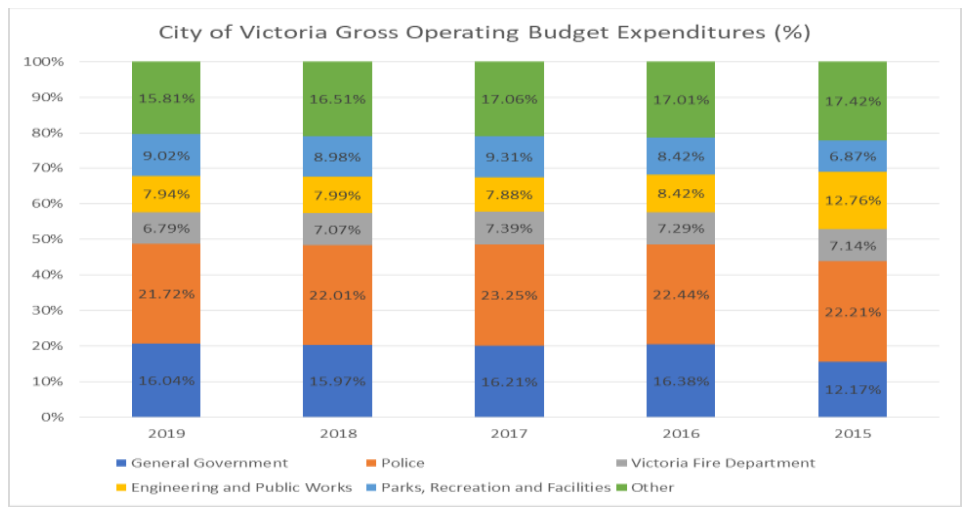

The above graph is a breakdown of the City of Victoria's expenditures. The most significant costs were for the Police that averaged about $22 \%$ of total operating costs a year. The next significant cost the General government, followed by Parks, recreation and facilities, then engineering and public works, and finally Victoria Fire Department. Other included categories that were not relevant to this report.

\subsection{Collingwood}

Collingwood as a sample of Canadian Town is refreshing its long-term vision, and accompanying Communitybased Strategic Plan (CBSP) that sets out what Council intends to focus on to achieve this vision to meet the needs of the Town's current residents, enhance public spaces, manage development and growth, and boost public access to the waterfront. https://engage.collingwood.ca/community-based-strategic-plan. In the meantime, the preservation of natural resources is one of the necessities of continuous development. These resources such as water, soil, vegetation, air, etc. are essential for the survival of urban life, in a town like 
Collingwood wastewater plant is currently running at 63 percent capacity, though a small number of local sewers do have capacity issues (Simco.com, Thursday, Aug 20). In this case, it is necessary to be able to maintain sustainable living resources in cities.

Graph 10

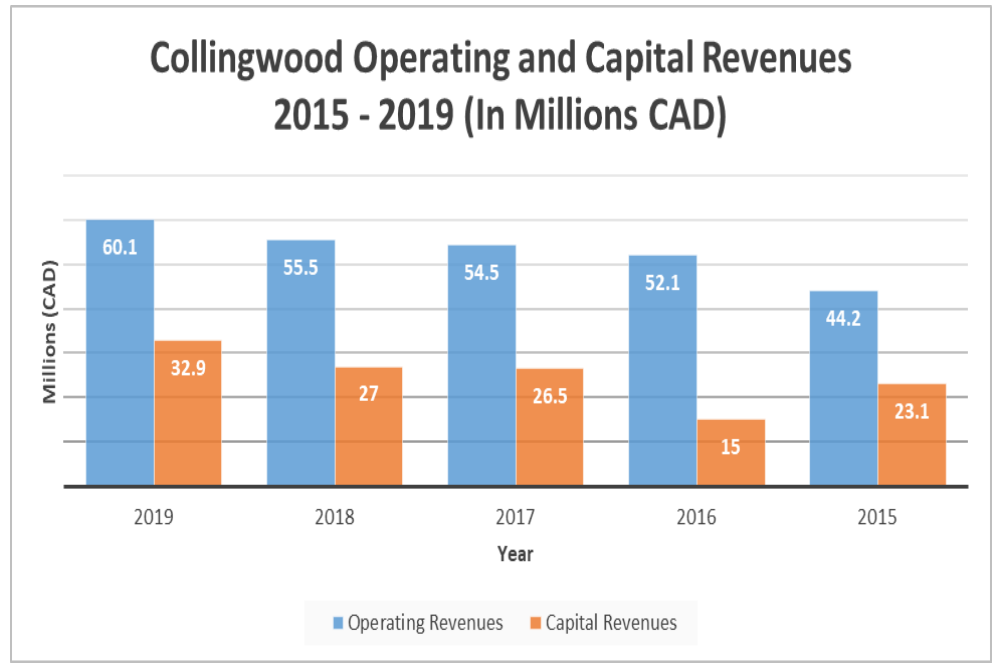

Operating revenues have been consistently increasing for Collingwood within the last five years to cover municipal programs and services. Capital revenues don't show a consistent increasing so we can see a major decline in 2016.

Graph 11

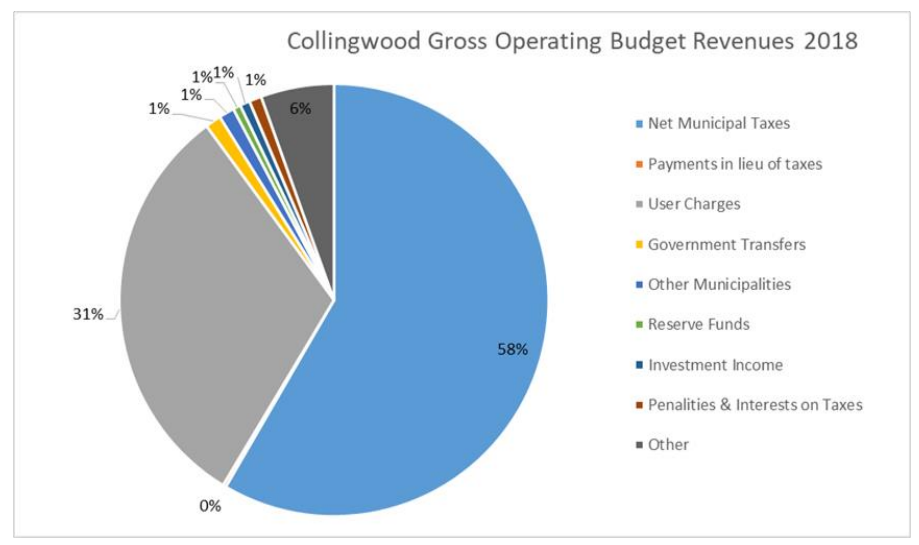

Property tax revenues are also Collingwood's single largest revenue source (58\%) followed by user fees, including water, wastewater, solid waste and parking services (31\%) in the last three years. To sum, property taxes are the highest revenue source in all three cities within the last three years with Collingwood having the highest percentage at 58\%, Victoria at 55\% and Toronto the lowest at 33\%. However, Toronto receives significant provincial subsidies because it must fund and deliver a wide range of programs and services that extend beyond the mandate of smaller municipalities. 


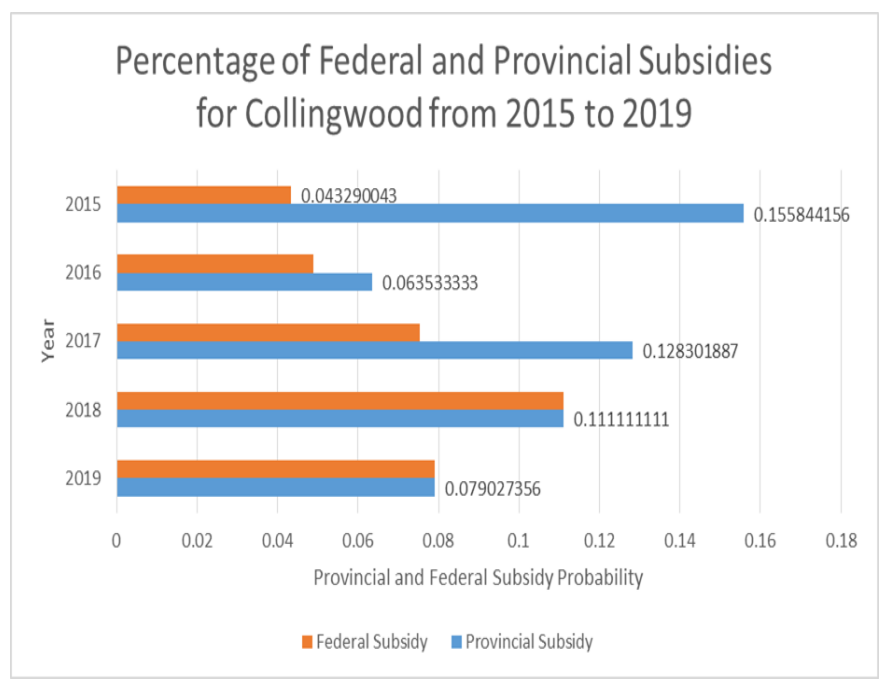

Collingwood also receives more subsidy from the provincial government as shown in 2015 top 2017. However, in 2018 and 2019 the city reported both provincial and federal subsidies as one total.

\section{Graph 13}

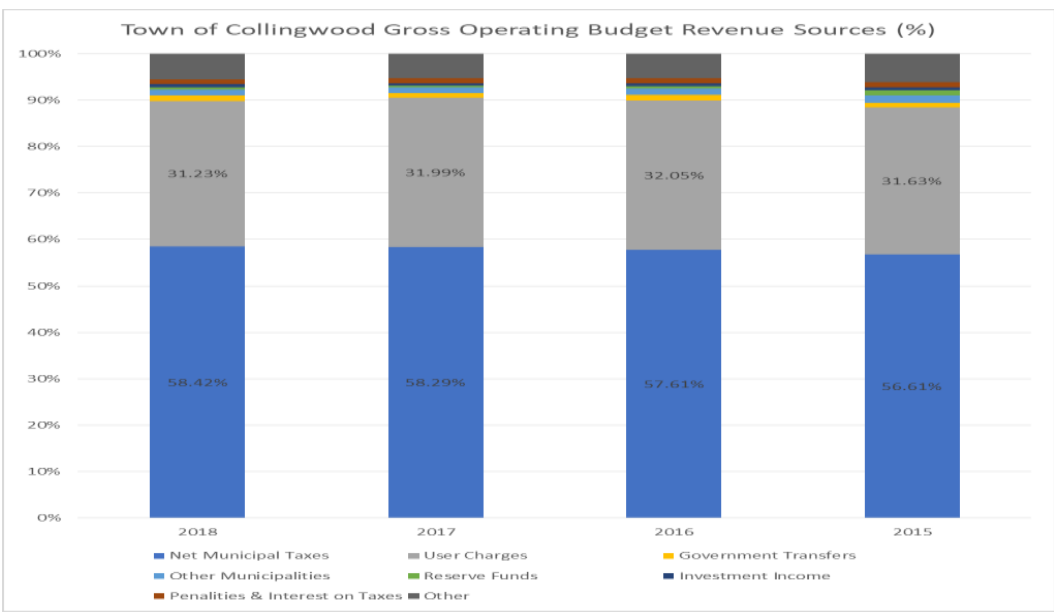

The above graph is a breakdown of the Town of Collingwood's Gross operating budget revenue sources from 2018 - 2015. The most significant sources were from Net municipal taxes, mostly property tax, which made up nearly $60 \%$ of the town's revenues. The next significant source was from user charges making up nearly onethird of their sources. Other sources, in no particular order, included government transfers, monies from other municipalities, reserve funds, investment income, and penalties \& interest on taxes. 


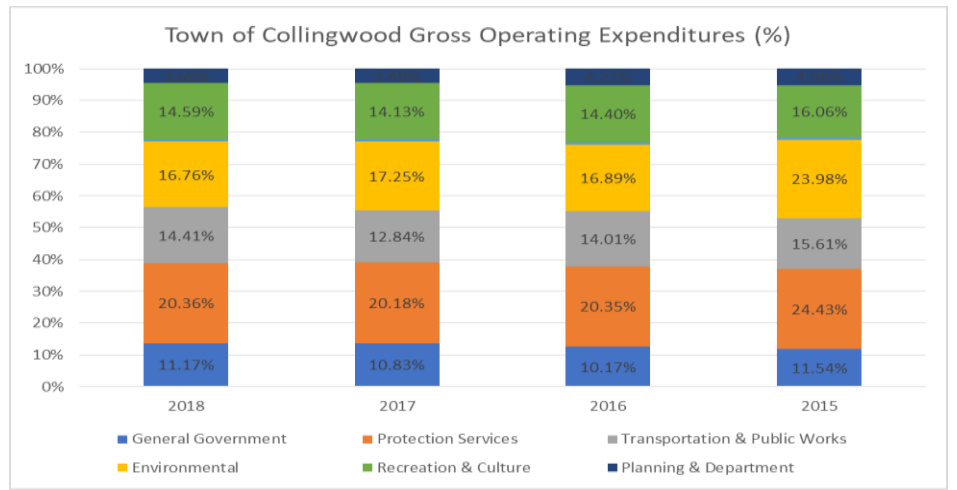

The above graph is a percentage breakdown of the Town of Collingwood's Gross operating expenditures. The most significant cost was protection services that made up over $20 \%$ of their expenditures in each year. The next sign was environmental expenditures, followed by recreation and culture, then transportation \& public works, and then general government, and finally planning \& department.

Municipal governments in Canada typically maintain balanced budgets, but they are also subject to restraints on transfer payments imposed by their provincial governments. How the cities then allocate that money is determined by various factors. These include whether they have large populations of immigrants or the elderly to serve, the basis for the local economy - such as whether it is fuelled by resources, manufacturing or service industries - the degree of homelessness, relationships with public-sector unions, and the costs of compliance to federal standards for such things as wastewater. Unfunded liabilities may also put pressure on a city's payroll and create an actuarial deficit for its pension plans, resulting in tighter provincial scrutiny.

The small towns in Canada are unique in their character and relationship with the province in connection to economy and financial situation and urbanization. One of the most pertinent challenges that towns and local communities have faced in Collingwood is a lack of financial autonomy, in which they have tried to remedy through community support for business incubators to jumpstart companies and support investment (Federation of Canadian Municipalities, 2020). From the research in Canada, it appears that towns are the central space for the promotion of technological advancements, sustainable infrastructure and citizen participation (FCM, 2020). This is partially due to the demographics of the space, their capacity for generating revenues, natural resources, and openness to investment in their communities that prioritize the interests of the locals (FCM, 2020). Towns are an important place that local communities play an essential role in holding an opportunity to support for matters of governance like public infrastructure and impact the revenue; these spaces obtain therein influencing public and private expenditure.

Concerning the sustainability of our current lifestyles from both an environmental and financial perspective, it is clear that significant changes need to be made. Central to this discussion is a focus on combatting climate change and building a resilient future, and a commitment to developing better economic conditions through increased citizen participation.

The tendency towards increasing consumption and exploitation of natural resources, it is clear that this lifestyle cannot be followed anymore, and the current lifestyle needs to be changed. To reach this point we need to change the dominant mindset. Another challenge is that current lifestyle ties with market and economy trends which highly depended on the current capitalist system and its approach to life in the world. So to change that foundation, the model of sustainable urbanism is needed so that we are able to analyze and 
discuss all aspects of the quality of life in this model to deeply understand the criteria of it. With these renewed focuses have to be a commitment to reorienting our current urban and land-use planning traditions along with challenge predominant political and economic systems of power.

Graph 15

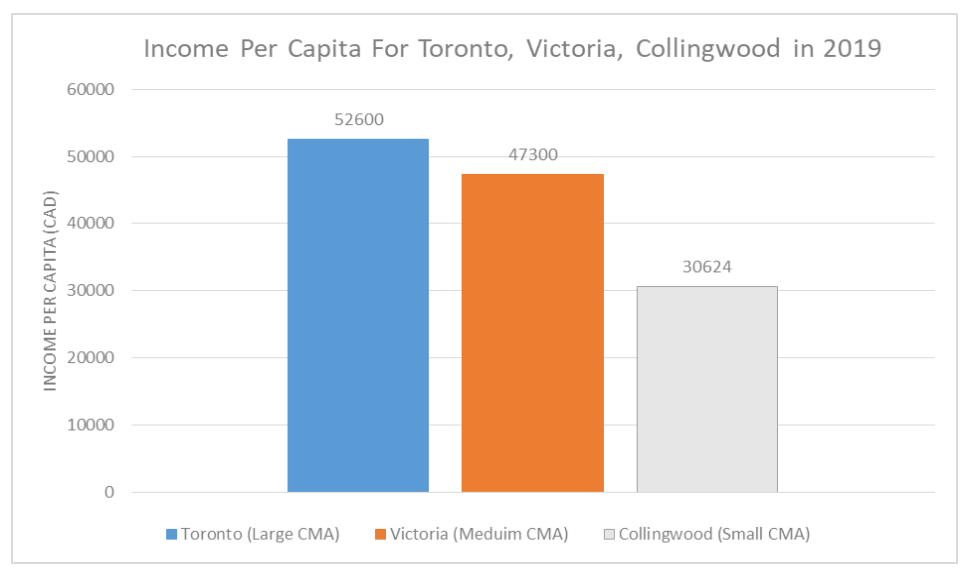

The main factor for the financial health of cities is income (particularly the income of citizens that indicates the level of standard of life.) Toronto as the largest CMA has the highest income per capita $(\$ 52,600)$ with Collingwood as the smallest CMA having the least $(\$ 30,624)$ followed by Victoria $(\$ 47,300)$. Hence, the larger the CMA the higher the income per capita.

Graph 16

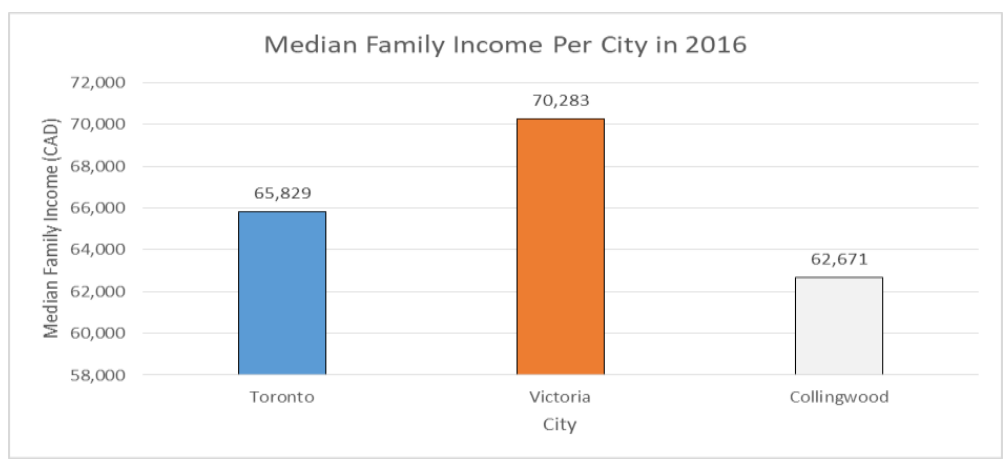

Meanwhile, in 2016, Victoria had the highest median family income at $\$ 70,283$ while Collingwood had the lowest at $\$ 62,671$. The data shows there is a direct relationship between income per capita and the size of the city. 
Graph 17

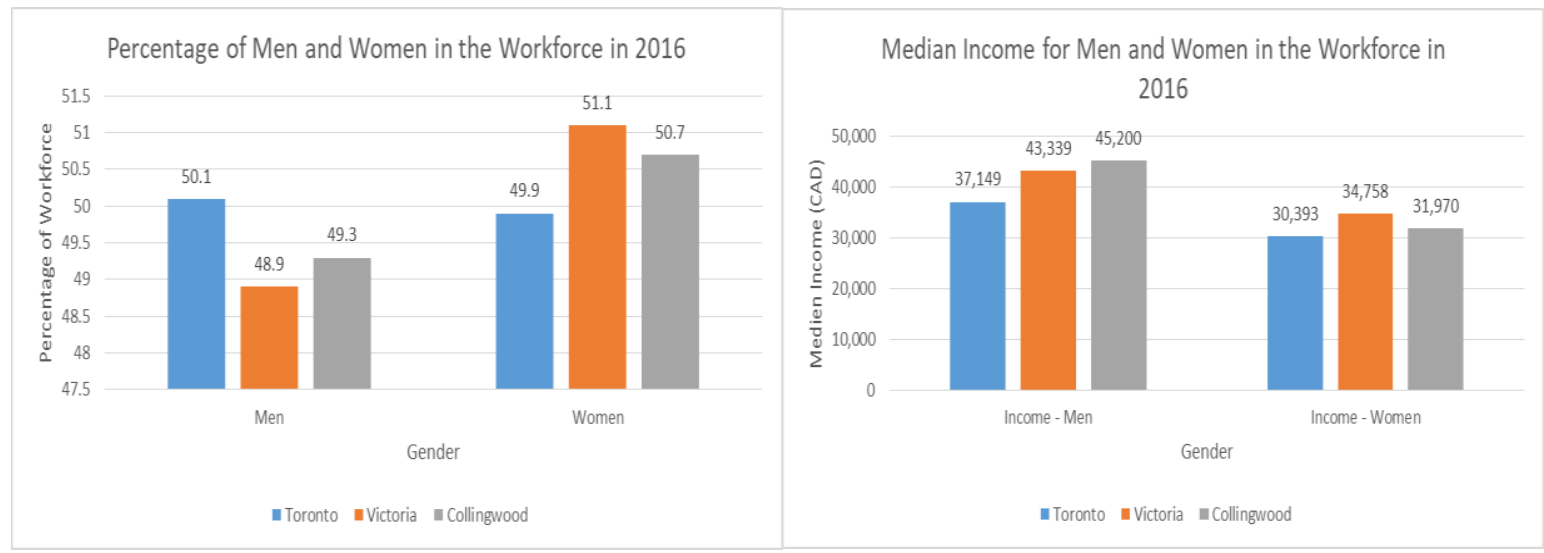

In Toronto, the percentage for men and women in the workforce is comparable $(50.1 \%$ and $49.9 \%$ respectively). However, this differs for Victoria and Collingwood with women slightly outnumbering men. Victoria has the highest percentage of women to men ( $51.1 \%$ and $48.9 \%$ respectively) followed by Collingwood ( $50.7 \%$ to $49.3 \%$ respectively).

The median income is lowest in Toronto for both men and women with Collingwood having the highest income for men and Victoria for women. There is a gender discrepancy in all three cities with men receiving higher wages than women. So the data shows although small cities provide more opportunity for women to enter the labour market.

\section{Conclusion}

Through an exploration of municipal finance on a multispectral level in looking at the cities of Toronto and Victoria along with the town of Collingwood, this paper analyses models of urban economy and sustainable city development. In investigating urban economics it is clear that urban management rooted in capitalism has governed many cities as mechanisms to maximize on financial capital and garner municipal autonomy. Socialist economic conditions and ideological principles employ an approach that emphasizes equity in access to social institutions, which is supported by larger national government institutions. In centering the critiques of both of these systems, countries have explored a model, which limits the powers of urban authorities through relationships that rely on the federal and provincial powers. Another evolving model follows an unplanned operation approach that utilizes a mix of principles of political economies and sustainability discourses in managing city-building practices. These different models approach capacity building in cities in various ways, which is a central indicator of how sustainable development, and citizen participation are employed and regulated. The role of urban density and municipal finance in transforming the capacities and political economies of cities must prioritize balanced sustainability measures and creatively employ effective implementation steps.

The case of Toronto as a large urban center is an important example of the variety of sectors and services involved in municipal finance. Additionally the data on Toronto shows the role of urban development and the significance of the Ontario government support in revenue generated from property tax and provincial subsidies. The City of Victoria as a mid-sized city informs us on the complexities of embracing a future of commercial investment. Making an effort to showcase sustainable environments, while facing various 
challenges such as, consolidating local governance measures and stabilizing municipal finance measures. The Town of Collingwood as a smaller urban center offers insight into the importance of investing in natural resources and participating in community development in order to maintain city infrastructure that sustains economic growth. With respect to promoting sustainable development and changing trends of consumption and exploitation in urban centers, it is necessary to adopt alternative mindsets that promote urban resilience and more equitable approaches to political economies. These efforts include assessing the financial health of cities and addressing topics of income disparity and gender equality, which are directly linked to sustainability.

In order to better the quality of life of individuals and commit to urban models of sustainability, this work contends that increased resources for urban economies and municipal finance are required in order for urban centers to balance self-reliance and external partnerships. Central to this discussion of prioritizing sustainable resources are fundamental commitments to gender parity, more equitable socioeconomic conditions, and fairer decision-making bodies. In the future, further research is required on models of sustainable urbanism and balancing public and private expenditure with city infrastructure and the needs of local communities.

\section{References}

Adlakha. D, Samis, J.F (2020) Why urban density is good for health - even during a pandemic, http://qpol.qub.ac.uk/why-urban-density-is-good-for-health-even-during-a-pandemic/ Posted 27th July 2020

Allen J. Scott Michael Storper (2015) The Nature of Cities: The Scope and Limits of Urban Theory Volume39, Issue1, Pages 1-15

Boltanski, Luc and Eve Chiapello. 2005. The New Spirit of Capitalism. London: Verso

Castán Broto, V., Trencher, G., Iwaszuk, E. et al. Transformative capacity and local action for urban sustainability. Ambio 48, 449-462 (2019). https://doi.org/10.1007/s13280-018-1086-z

Census Canada, 2016

City Of Victoria, British Columbia, Annual Report, Year ended December 31, 2018.

Côté, A., \& Fenn, M. (2014). Provincial-Municipal Relations in Ontario: Approaching an Inflection Point (pp. 1-60, Rep. No. 17). Institute of Municipal Finance and Governance.

Folke, C., S.R. Carpenter, B. Walker, M. Scheffer, T. Chapin, and J. Rockström. 2010. Resilience thinking: Integrating resilience, adaptability and transformability. Ecology and Society 15: 20.

Garud, R., and P.R. Nayyar. 1994. Transformative capacity: Continual structuring by intertemporal technology transfer. Strategic Management Journal 15: 365-385.

Simco.com, Thursday Aug 20 
Wakely Patrick, Capacity building for better cities, DPUNEWS, Journal of the Development Planning Unit, University College London. University College London, downloaded Aug 2020. https://www.gdrc.org/uem/capacity-build.html

Wolfram, M. 2016. Conceptualizing urban transformative capacity: A framework for research and policy. Cities 51: 121-130. 